\title{
ANÁLISE DA VIABILIDADE ECONÔMICA DA INTEGRAÇÃO DE CÉLULAS A COMBUSTÍVEL NAS PLANTAS DE CLORO-SODA PARA UTILIZAÇÃO DO HIDROGÊNIO GERADO NO PROCESSO
}

\author{
José Mauro Fernandes Braga, M. Sc. ${ }^{1}$ \\ Peter Seidl, D. Sc. ${ }^{2}$ \\ Waldimir Pirró e Longo, D. Sc. ${ }^{3}$
}

\begin{abstract}
Resumo - Este trabalho tem como objetivo levantar as condições para a viabilidade econômica da aplicação do hidrogênio industrial, gerado em planta de produção de cloro soda, em sistemas de célula a combustível. Utilizaram-se os métodos do Valor Presente Líquido (VPL) e da Teoria das Opçôes Reais (TOR), para avaliar economicamente a integração, com base nos parâmetros custo do investimento, volatilidade, taxa de juros livre de risco e taxa de dividendos. Conclui-se que a factibilidade econômica do empreendimento depende, nas condições brasileiras atuais, de ação política governamental.
\end{abstract}

Palavras-chave: célula a combustível, hidrogênio industrial, plantas de cloro-soda.

Abstract - This work aims to demonstrate the economic viability of the application of industrial hydrogen in fuel cell systems by analysing the advantages and disadvantages of this investment in $\mathrm{HCl} / \mathrm{NaOH}$ plants. Using the Present Liquid Value and the Real Options Theory an economic evaluation will be made of the integration of fuel cell system in these plants, based on investment cost, volatility, among other parameters. It's concludes that using atual Brazilians parameters economical feasibility the integration depends on government political actions.

Keywords: fuell cell, $\mathrm{HCl} / \mathrm{NaOH}$ plants, industrial hydrogen.

\section{INTRODUÇÃO}

A carência de adequada infra-estrutura de distribuição de hidrogênio é um dos maiores empecilhos para o desenvolvimento e comercialização industrial das células a combustível.

Em diversos estudos, como, por exemplo, no National Hydrogen Energy Roadmap (US DOE 2002a), cita-se que as plantas de cloro-soda podem ser as mais importantes fontes industriais de hidrogênio puro, confirmado em laboratório, sendo o mais fácil e econômico combustível para as células a combustível.

As plantas de cloro-soda, um segmento básico da indústria química, produzem, por eletrólise, cloreto de sódio e soda cáustica, e o hidrogênio como subproduto, com uma produção mundial de 50 milhões de MT (toneladas métricas) por ano de soda e uma relevante quantidade estequiométrica de cloro.

A maioria das plantas queima o hidrogênio produzido como combustível, complementada por gás natural (GN), e em alguns casos, com a aquisição de vapor, já que o processo produtivo é energo-intensivo, exigindo muita energia elétri-

\footnotetext{
${ }^{1}$ Professor da Escola de Engenharia da UFF - Universidade Federal Fluminense. Doutorando EQ - UFRJ - Universidade Federal do Rio de Janeiro (jmfbraga@oi.com.br).

2 Professor Orientador - UFRJ (pseidl@eq.ufrj.br).

${ }_{3}^{3}$ Professor Co-Orientador. Professor do NEST/UFF - Universidade Federal Fluminense UFF- NEST (Núcleo de Estudos Estratégicos) - Instituto de Ciências Humanas e Filosofia (ICHF), Campus de Gragoatá, 3o andar (wlongo@nitnet.com.br).
} 
ca para eletrólise e muito vapor para concentrar a soda cáustica.

Uma pequena parte do hidrogênio (12\%) é utilizada internamente como matéria-prima para a produção de ácido clorídrico - HCL, e, neste caso, seu valor é tão alto que a utilização como energia para células a combustível é seguramente improvável economicamente.

Em algumas regióes no mundo, como na China e na Î́ndia, é muito freqüente a não-utilização de parte do hidrogênio produzido - mais do que $20 \%$-, sendo este assim liberado para a atmosfera, devido à ausência de infra-estrutura nas plantas e ao fato de estas não serem interconectadas.

Este artigo tem como objetivo a análise da viabilidade econômica da integração de células a combustível, nas plantas de cloro-soda para utilização do hidrogênio gerado no processo, por meio da avaliação econômico-financeira, utilizando a metodologia do valor presente líquido - VPL e a teoria das opções reais - TOR, tendo em vista a incerteza associada ao projeto.

Com essa metodologia, pretende-se avaliar a robustez da avaliação econômico-financeira a ser obtida, bem como a flexibilidade estratégica e administrativa, para obter o valor das opçōes implícitas em investimento de capital, como o do projeto da integração referida.

Em virtude da natureza do objetivo deste trabalho, houve uma seleção criteriosa de empresas do segmento cloro-soda, por meio da análise do desempenho de cada uma delas, tendo sido enviado, a duas das maiores empresas brasileiras do segmento cloro-soda, questionários, muitos dos quais retornaram parcialmente respondidos.

À medida que os aspectos relevantes foram identificados nas fontes de informaçôes inicialmente selecionadas, novas questões emergiram, com vistas à compreensão ou o conhecimento do estado da arte. Tal fato exigiu a inclusão de outras fontes, até serem suficientes para dar consistência ao tratamento do problema e atender à questão da utilização do hidrogênio produzido em seus respectivos processos primários de produção de energia elétrica por meio de células a combustível, uso que objetiva buscar a redução do custo do insumo de maior valor para a produção de seus produtos finais, cloro e soda cáustica, possibilitando a integração proposta.

\section{RECUPERAÇÃO DA ENERGIA}

Segundo a empresa Nuvera, localizada na Itália, os sistemas de célula a combustível podem permitir a recuperação de até $20 \%$ da energia usada para eletrólise nas plantas de cloro-soda, em função de três critérios básicos:

- operação das células a combustível em baixa pressão, porque a energia necessária para comprimir o hidrogênio e o ar não pode ser plenamente recuperada;

- utilização direta da célula a combustível na conversão da energia produzida em DC para CA em paralelo com retificadores na sala de célula, evitando o alto custo e a ineficiência da transformação de potência; e

- recuperação máxima do hidrogênio, obtido com um projeto detalhado e bem adaptado ao sistema da célula a combustível.

Considerando que a necessidade mundial das indústrias de cloro-soda para seu processo produtivo é da ordem de $15.000 \mathrm{MW}$, é teoricamente possível economizar 3.000 MW, sendo provável que até o ano de 2015, mais do que $1.000 \mathrm{MW}$ sejam economicamente factíveis, o que seguramente representa um dos mais promissores caminhos do desenvolvimento industrial das células a combustível.

A confirmação da importância desta solução já se configura nos fabricantes mundiais de equipamentos para o segmento cloro-soda, através dos estudos dos projetos nas instalações Freeport Dow, no Texas-EUA numa parceria GM-DOW e no futuro projeto AKZO NOBEL-NedStack para Botlek, na Holanda e nos fabricantes nacionais, como Electrocell, Unitech e Novo Cell.

Os laboratórios da Nuvera F/C e DNTE C/A (Chlor-Alcali), localizados em Milão, na Itália, confiam neste desenvolvimento e estão propondo projetos de demonstração em parceria com indústrias de cloro-soda, para instituições interessadas em promover e financiar inovação tecnológica e aplicação em célula a combustível.

Os laboratórios dos citados fabricantes, que são próximos um do outro, organizaram um teste em parceria, alimentando stacks de células a combustível com o hidrogênio produzido por células 
eletrolíticas do tipo membrana, com resultado bem satisfatório.

O grande interesse nas plantas de clorosoda para recuperação de hidrogênio industrial é que o melhor hidrogênio disponível é produzido pelas células eletrolíticas do tipo membrana, uma vez que ele:

- é suficientemente puro, devido ao estágio de separação, eliminando vestígios corrosivos alojados, para atingir temperatura e umidade corretas; e

- está, com freqüência, sob um nível de pressão suficiente (1,25 bar absoluto) para alimentar diretamente a célula a combustível, dispensando estágio de compressão.

\section{VANTAGENS E DESVANTAGENS}

A introdução da célula a combustível nas plantas de cloro-soda apresenta interessantes vantagens e somente poucas menores desvantagens:

a) Vantagens

- o ambiente industrial se ajusta muito bem à necessidade de curva de aprendizado para o desenvolvimento das células a combustível;

- os sistemas de célula a combustível podem migrar de um ambiente bastante favorável a outro em que as realidades industriais ganham em interação de faixa de potência $(200-5000 \mathrm{KW})$;

- a introdução de sistemas de células a combustível acontece num ambiente tecnológico onde a nova tecnologia pode ser facilmente aceita pelos operadores;

- o sistema de célula a combustível pode ser escolhido de forma a ser facilmente operável, sem impactar a rotina normal de produção;

- não há necessidade de novas regulações, padrões, nem permissões especiais, porque o hidrogênio já está presente e usado no local da planta; e

- os custos de operação para grande escala e de testes são baixos, já que a infra-estrutura do hidrogênio já está quase completamente estabelecida. b) Desvantagens

- as plantas de cloro-soda são um dos maiores clientes das empresas fornecedoras de energia elétrica e, normalmente, obtêm o menor preço de energia elétrica do mercado e dentro de um código mútuo de sigilo total acerca do preço acordado; e

- como conseqüência o custo do KWh produzido nas plantas de cloro-soda pode ser competitivo principalmente onde o preço da energia é suficientemente alto, ou onde a "energia verde" é favorecida pelos governos.

- A recuperação do hidrogênio, produzido nas plantas do segmento cloro-soda que usam células eletrolíticas do "tipo membrana", atualmente presentes em mais de $50 \%$ da capacidade mundial total, é o caso mais favorável. Entretanto, também as tecnologias de mercúrio e diafragma podem ser igualmente adequadas, mas requerendo um processo mais complicado.

\section{CÉlula A COMBUSTível}

O núcleo de uma célula a combustível constitui-se do empilhamento (stack) de células unitárias que representam $27 \%$ do custo total, sendo um dos maiores insumos, e placas separadoras bipolares (SERRA et al., 2005). Cada célula unitária é formada pelo conjunto eletrodo (anodo), membrana e eletrodo (catodo), conhecido como MEA (membrane eletrode assembly), que representa o componente mais oneroso do stack.

O tempo de operação limite para um certo decréscimo de desempenho de uma célula combustível, define a vida útil do stack da mesma, que varia dramaticamente nas diferentes aplicações, e assim, a vida útil é relacionada às condiçôes de operação e ao grau permitido de decréscimo de desempenho. As exigências para os stacks nas aplicações em plantas de cloro-soda são de uma vida útil de 40.000/50.000 horas (CAMPBELL, 2001) e uma tensão tão estável quanto possível.

Por essa razão, a previsão da vida útil dos sistemas projetados pelos fabricantes pode atingir 4 anos (por conseguinte, a vida normal das membranas das plantas de cloro-soda), e após esse 
período os stacks podem ser completamente substituídos.

A recuperação e o recondicionamento de todos os componentes metálicos do stack e a reciclagem dos metais nobres da membrana catalítica, ajudarão a reduzir o custo de renovação da célula a combustível.

Comercialmente, as células de ácido fosfórico-PAFC, proposta neste trabalho estão no mercado desde o ano 90 e apesar de operarem em baixa temperatura, apresentam a possibilidade de absorverem rejeitos térmicos na temperatura de $200^{\circ} \mathrm{C}$, existindo mais de 250 unidades implantadas e exaustivamente testadas, inclusive no Brasil com 5 unidades.

\section{DETERMINAÇÃO DE PARÂMETROS}

Para realizar a análise proposta neste trabalho, foram contatadas, com sucesso, as duas maiores empresas do setor cloro-soda atuantes no Brasil, obtendo-se dados que permitiram a elaboração dos cálculos que se seguem:

1) Cálculo da potência disponível na empresa A:

- volume de $\mathrm{H}_{2}$ produzido no processo industrial - 11.382 t/ ano 2007;

- quantidade de $\mathrm{H}_{2}$ utilizada para produção de $\mathrm{HCl}$ - 241 t/ ano;

- PCI (poder calorífico inferior) do $\mathrm{H}_{2}$ (SERRA et al., op. cit.) - $119.600 \mathrm{KJ} / \mathrm{kg}$;

- potência teórica $\left(\mathrm{P}_{0}\right)$

(1) $\mathbf{P} 0=\mathbf{P C I} \times \mathbf{Q}$ (BURANI et al., 2003)

$\mathrm{P}_{0}=\left(11.382-241\right.$ tonH $\left._{2} / \mathrm{ano}\right)(119.600$

$\mathrm{KJ} / \mathrm{kg}) \quad\left(10^{3} \mathrm{~kg} / \mathrm{ton}\right) \quad(1 \mathrm{ano} / 8760 \mathrm{~h})$ $(1 \mathrm{~h} / 3600 \mathrm{~s})$

$\mathrm{P}_{0}=42252,1 \mathrm{KJ} / \mathrm{s}(\mathrm{KW})$;

- potência elétrica a ser gerada - $\mathrm{P}$

(2) $\mathrm{P}=\mathrm{Poy}$, e supondo rendimento da célula combustível (y) igual a 0,36 , vem

$\mathrm{P}=42.252,1 \times 0,36=15,21 \mathrm{MW}$

2) Cálculo da potência disponível na empresa $\mathrm{B}$ :

- volume de $\mathrm{H}_{2}$ produzido - 7.100 t/ano 2007;

- quantidade de $\mathrm{H}_{2}$ utilizada no $\mathrm{HCl}-$ 4.000 t/ano;
- PCI $\mathrm{H}_{2}-119.600 \mathrm{KJ} / \mathrm{kg}$

- potência teórica $\left(\mathrm{P}_{0}\right)$

(1) $\mathrm{P}_{0}=\mathrm{PCI} \times \mathrm{Q}$ (BURANI et al., op. cit.) $\mathrm{P}_{0}=(7.100-4000) \times 119.600 \times 10^{3} \mathrm{x}$ $1 / 8.760 \times 3.600=11.756,7 \mathrm{KW}$

- potência elétrica a ser gerada - P $\mathrm{P}=\mathrm{P}$ on

$P=11.756,7 \times 0,36=4,23 \mathrm{MW}$

3) Custo de geração elétrica com uma célula a combustível, CoE (SERRA et al., op. cit.)

- Parcela do custo do combustível (comb) em R\$/ KWh:

- Comb = preço por unidade energética/ eficiência elétrica.

- Comb $(\mathrm{R} \$ / \mathrm{MWh})=$ [preço por unidade energética $(\mathrm{R} \$ / \mathrm{GJ})]$ x [3.6 GJ/ MWh]/eficiência.

- Parcela do custo de O\&M (OM) em R\$/MWh:

- Célula a combustível do tipo PAFC (Phosforic acid fuel cell) operada em campo U.S. DoD. ${ }^{4}$

$$
\mathrm{OM}=0,010 \mathrm{US} \$ / \mathrm{KWh}
$$

- Custo do capital investido (aquisição e instalação do equipamento, Cap., em $\mathrm{R} \$$ /MWh).

- Cap = custo anualizado do investimento/ energia gerada.

- Custo anualizado = investimento $\mathrm{x}$ fator de anualização (F).

- Energia gerada em 1 ano $(\mathrm{MWh})=$ potência nominal da célula a combustível (KW) x 8.760 (horas/ano) x fator de capacidade $\mathrm{x}$ 0,001 MW/KW

- Fator de capacidade = energia efetiva gerada em 1 ano (8.760), em MWh/ energia máxima, se a célula a combustível operasse $8.760 \mathrm{~h} / \mathrm{ano}$ na sua potência nominal.

Rearranjando as equações anteriores:

- Cap = Investimento $(\mathrm{R} \$ / \mathrm{KW}) \times \mathrm{F} /$ (fator de capacidade x $8.760 \mathrm{MWh}$ x $\mathrm{KW}^{-1}$ ).

\footnotetext{
${ }^{4}$ http://www.dodfuelcell.com/pafc/site/performance. php3_jan2003.
} 
- O fator de anualização (F) é calculado por $F=\left\{\operatorname{ix}(1+i)^{n} /\left\{(1+i)^{n-1}\right\}\right.$, onde:

$\mathrm{i}=$ taxa de retorno do investimento $=15 \%$ ao ano $=0,15$;

$\mathrm{n}$ = vida útil do equipamento ou prazo de retorno do investimento, inicialmente $40.000 \mathrm{~h}$ ou 5 anos, prazo máximo para o comprador da célula a combustível ter o retorno do seu investimento, sendo que, com as mudanças tecnológicas esperadas, o prazo seria de 10 anos;

Assim, teremos $\mathrm{F}$ ( $15 \%$ aa, 5 anos $)=0,2983$ e F $(15 \%$ aa, 10 anos $)=0,1992$

Dessa forma, o CoE (Custo de energia elétrica gerada) em US\$/MWh é:

(3) $\mathrm{CoE}$ (US\$/MWh) = 3,6 Pcomb (US\$/ GJ)/ ytotal + 103. CO\&M (US\$/KWh) + FA (j,n)/ 8,76 . FCAP . CaC (US\$/KW)

Como Pcomb $=0$, vem

$\mathrm{CoE}=10^{3} \times 10^{-2}+(0,2983 / 8,76 \times 0,7143)$ x $2,6 \times 10^{3}$

$\mathrm{CoE}=10+0,1239 \times 10^{3}=133 \times 1,7 \mathrm{R} \$ /$ MWh

$\mathrm{CoE}=227,63 \mathrm{R} \$ / \mathrm{MWh}$, para $\mathrm{n}=5$ anos $\mathrm{e}$ $157,76 \mathrm{R} \$ / \mathrm{MWh}$ para $\mathrm{n}=10$ anos

Foram considerados como parâmetros do modelo, já que o Pcomb é nulo, o investimento e o fator de capacidade, e uma análise de sensibilidade monoparamétrica e biparamétrica mostra a correlação linear/simétrica e linear/assimétrica, respectivamente. $\mathrm{E}$, assim, uma variação relativa no investimento de $10 \%$ (positiva ou negativa) resulta numa variação de $3,84 \%$ (positiva ou negativa) no valor do $\mathrm{CoE}$, como é mostrada a especificação do caso-base da análise de sensibilidade a seguir:

Tabela 1. Análise de sensibilidade da integração de sistemas de célula a combustivel dentro das plantas de cloro-soda para utilização do hidrogênio industrial

\begin{tabular}{|c|c|c|}
\hline Parâmetro & $\begin{array}{l}\text { Valor no } \\
\text { caso-base }\end{array}$ & Faixa de variaçãao \\
\hline FCAP & 0,7143 & $\begin{array}{c}-40 \% a+40 \%: \\
0,4286-1,00\end{array}$ \\
\hline $\mathrm{Cac}$ & $\begin{array}{c}2.600 \mathrm{US} \$ \text { / } \\
\text { KW }\end{array}$ & $\begin{array}{c}-40 \% a+40 \%: \\
1.560-3.640\end{array}$ \\
\hline $\begin{array}{c}\text { FAC } \\
(15 \%, 5)\end{array}$ & 0,2983 & constante \\
\hline $\mathrm{CO} \& \mathrm{M}$ & $\begin{array}{c}\text { 0,01 US\$/ } \\
\text { KWh }\end{array}$ & constante \\
\hline
\end{tabular}

Os valores da energia elétrica fornecida pelas concessionárias no atendimento às duas empresas não foram informados pelas mesmas, mas obtidos no site da ANEEL, o que permitiu a obtenção das tarifas do subgrupo A1 (230 KV ou mais), listadas na próxima tabela:

Tabela 2. Tarifas do subgrupo $A 1$

(230 KV ou mais) para as duas empresas

\begin{tabular}{|c|c|c|c|c|}
\hline & \multicolumn{2}{|c|}{ Fornecedora da Indústria A } & \multicolumn{2}{c|}{ Fornecedora da Indústria B } \\
\hline & Demanda R\$/KW & Consumo R\$/KW & Demanda R\$/KW & Consumo R\$/KW \\
\hline Ponta Seca & 25,62 & 163,54 & 7,06 & 205,85 \\
\hline Ponta Úmida & 25,63 & 143,04 & 7,06 & 186,09 \\
\hline Fora de ponta seca & 6,69 & 115,74 & 0,00 & 128,03 \\
\hline $\begin{array}{c}\text { Fora de ponta } \\
\text { úmida }\end{array}$ & 6,69 & 115,74 & 0,00 & 116,57 \\
\hline
\end{tabular}


Portanto, uma redução de 28 a $37 \%$ sobre o valor do CoE do caso-base, na empresa $\mathrm{A}$, e na empresa $\mathrm{B}$, uma redução de 10 a $18 \%$, igualaria o valor de referência. Dessa forma, observa-se que uma melhoria na tecnologia, aumentando a eficiência e reduzindo os custo de aquisição das células a combustível num cenário no qual uma tecnologia energética e ambientalmente mais eficiente possa ser objeto de incentivos legais nas políticas governamentais, o custo final é competitivo.

Lokurlu et al. (2003), em estudo teórico sobre análise de custo da energia elétrica em células a combustível, concluíram que à medida que se aumenta o tempo de operação de uma planta de $200 \mathrm{KWe}$ - a mesma a ser proposta neste estudo -, evidentemente dilui-se o investimento, reduzindo-se o seu peso sobre o custo da eletricidade gerada, para um quinto do investimento inicial, confirmando as considerações expostas.

Tendo em vista que o $\mathrm{H}_{2}$ excedente da produção de $\mathrm{HCl}$ é atualmente utilizado na produção de calor, responsável por $40 \%$ do vapor necessário para o processo produtivo de $160 \mathrm{t} / \mathrm{h}$ e o restante sendo gerado por GN $\left(170.000 \mathrm{~m}^{3} /\right.$ dia) na empresa $A$, e na empresa $B, 2.100$ t/ano acrescidos de GN para queima em caldeiras, além da aquisição de vapor de empresa vizinha, torna-se necessária a determinação do consumo/ custo adicionais de GN e energia elétrica no caso da ausência de $\mathrm{H}_{2}$ nas empresas referidas, para atender à demanda energética necessária para o processo produtivo.

4) Consumo adicional de GN na empresa $A$

- poder calorífico inferior do GN (SERRA et al., op. cit.) $-35.780 \mathrm{KJ} / \mathrm{m}^{3}$

- potência teórica $\left(\mathrm{P}_{0}\right)-42.252,1 \mathrm{KJ} / \mathrm{s}(\mathrm{KW})$

- (4) $\mathrm{GNA}_{\mathrm{A}}=\mathrm{P}$ /PCI, substituindo os valores, vem

$\mathrm{GN}_{\mathrm{A}}=37.240 .419,96 \mathrm{~m}^{3} /$ ano.

5) Consumo adicional de GN na empresa $B$

- PCI do GN - $35.780 \mathrm{KJ} / \mathrm{m}^{3}$

- $\mathrm{P}_{0}-11.756,7 \mathrm{KJ} / \mathrm{s}(\mathrm{KW})$

- Consumo adicional de GN em mªno

(4) $\mathrm{GNB}=\mathrm{P}_{0} / \mathrm{PCI}, \operatorname{logo}$,

$\mathrm{GNB}=10.362 .193,72 \mathrm{~m}^{3} /$ ano.
6) Custo adicional de GN na empresa $A$

- custo de GN (SERRA et al., op. cit.) 22,21 R \$/GJ poder calorífico inferior do

GN $35.780 \mathrm{KJ} / \mathrm{m}^{3}$

- potência teórica

$$
\left(\mathrm{P}_{0}\right)-42.252,1 \mathrm{KW}
$$

- custo adicional de GN em R\$ de GN

(5) $R \$ G_{A}=P_{\text {comb }} \times P_{0}$

substituindo os valores, temos

$$
\mathrm{R}_{\mathrm{AGN}}=\mathbf{A} \text { 29.954.000,00 R\$/ano }
$$

7) Custo adicional de GN na empresa $B$

- Custo GN - 22.21 R\$/GJ

- poder calorífico inferior do $\mathrm{GN}-35.780$ $\mathrm{KJ} / \mathrm{m}^{3}$

- potência teórica

$$
\left(\mathrm{P}_{0}\right)-11.756,7 \mathrm{KW}
$$

- custo adicional de GN em R\$ de GN

(5) $\mathbf{R} \$ \mathrm{GNB}=\mathbf{P}_{\text {comb }} \times \mathbf{P}_{\mathbf{0}}$, logo, $\mathrm{R} \mathrm{GN}_{\mathrm{B}}=\mathbf{8 . 2 3 4 . 6 0 0 , 0 0 \mathrm { R } \$ / \text { ano }}$

8) Energia elétrica correspondente ao adicional de GN na empresa $A$

- $\mathrm{P}_{0}=42.252,1 \mathrm{KW}$

- $\mathrm{y}$ (rendimento da célula) $=0,36$

(6) $\mathbf{E}_{A}=\mathbf{P}_{0} \times$ y, substituindo os valores, $E_{A}=133.246 .222,60 \mathrm{KWh} /$ ano

9) Energia elétrica correspondente ao adicional de GN na empresa B

- $\mathrm{P}_{0}=11.756,7 \mathrm{KW}$

- $\mathrm{y}=0,36$

(6) $\mathrm{EB}=$ Pox $y, \log$, $E_{B}=37.075 .929,12 \mathrm{KWh} /$ ano.

10) Custo do $\mathrm{GN} / \mathrm{H}_{2}$ por MWh gerado na célula

- $1 \mathrm{Wh}=1 \mathrm{~W} \times 3.600 \mathrm{~s}=$ $3.600 \mathrm{WS}=3.600 \mathrm{~J}=3,6 \mathrm{KJ}$

- $1 \mathrm{KWh}=3,6 \mathrm{MJ}$

- $1 \mathrm{MWh}=3,6 \mathrm{GJ}$ (fator de conversão)

- y da célula =0,36

- necessidade para gerar $1 \mathrm{MWh}$ na célula: $1 \mathrm{MWh} / 0,36=2,77 \mathrm{MWh}$ de gás natural

- preço do $\mathrm{GN}=22,21 \mathrm{R} \$ / \mathrm{GJ}$

- custo do $\mathrm{GN}=22,21 \mathrm{R} \$ / \mathrm{GJ} \times 3,6 \mathrm{GJ} /$ MWh (fator de conversão) = 79,96 R $\$$ / MWh

(7) custo do GN/ $\mathrm{H}_{2}=79,96 \times 2,77, \log 0$ GN/ H2 $=\mathrm{R} \$ 221,49 / \mathbf{M W h}$ (custo do GN/ 
H2 por MWh gerado na célula, supondo o $\mathrm{H}_{2}$ que não foi usado nas caldeiras), que assim é a grande barreira no aquecimento do processo.

Obs.: $\mathrm{O}$ significado de $\mathrm{GN} / \mathrm{H}_{2}=\mathrm{R} \$ 221,49$ é que, para cada MWh de $\mathrm{H}_{2}$ a ser consumido na célula a combustível, deverá ser adicionado $1 \mathrm{MWh}$ de GN para geração em substituição ao $\mathrm{H}_{2}$ utilizado atualmente para esse fim.
A integração de sistemas de células a combustível com plantas do segmento cloro-soda para produção de energia em corrente alternada - CA representa uma solução para atingir ao mesmo tempo as metas de ampliação da competitividade industrial e a contribuição para uma política de redução de emissões.

As maiores empresas do segmento clorosoda no Brasil possuem atualmente o perfil energético apresentado a seguir:

Tabela 3. Perfil energético das duas empresas brasileiras do segmento cloro-soda

\begin{tabular}{|c|c|c|}
\hline & Empresa A & Empresa B \\
\hline $\begin{array}{l}\text { Produção anual de } \mathrm{H}_{2} \\
\text { usada na produção de vapor }\end{array}$ & $10.000 \mathrm{t} / \mathrm{ano}$ & $4.026 \mathrm{t} / \mathrm{ano}$ \\
\hline $\begin{array}{l}\text { Potência elétrica correspondente a } \\
\text { produção de } \mathrm{H}_{2} \text { acima referida }\end{array}$ & $42.252,1 \mathrm{KW}(\mathrm{KJ} / \mathrm{s})$ & $11.756,7 \mathrm{KW}(\mathrm{KJ} / \mathrm{s})$ \\
\hline $\begin{array}{l}\text { Energia elétrica correspondente ao } \\
\text { adicional de GN em KWh/ano }\end{array}$ & 133.246.222,60 KWh/ano & 37.075.929,12 KWh/ano \\
\hline Custo do GN necessário em $\mathrm{R} \$$ /ano & $29.954 .000,00$ & $8.234 .600,00$ \\
\hline Custo de EE por $\mathrm{CaC}$ & 227,63-157,76 R\$/MWh & 227,63-157,76 R \$/MWh \\
\hline Potência elétrica disponível & $15,21 \mathrm{MW}$ & 4,23 MW \\
\hline $\begin{array}{l}\text { Consumo adicional GN por } \\
\text { ausência de } \mathrm{H}_{2} \text { calculado }\end{array}$ & $37.240 .419,96 \mathrm{~m}^{3} / \mathrm{ano}$ & $10.362 .193,72 \mathrm{~m}^{3} / \mathrm{ano}$ \\
\hline $\begin{array}{l}\text { Consumo atual GN no processo } \\
\text { produtivo de energia térmica gerada } \\
\text { (60\%da energia térmica gerada) }\end{array}$ & $\begin{array}{c}170.000 \mathrm{~m}^{3} / \text { dia } \\
62.050 .000 \mathrm{~m}^{3} / \text { ano }\end{array}$ & \\
\hline $\begin{array}{l}\text { Consumo adicional GN por } \\
\text { ausência de } \mathrm{H}_{2} \text { informado } \\
\text { (40\% da energia térmica gerada) }\end{array}$ & $41.366 .666,7(40 \%) \mathrm{m}^{3} / \mathrm{ano}$ & \\
\hline $\begin{array}{c}\text { Energia elétrica correspondente ao } \\
\text { adicional de GN }\end{array}$ & 111.038,5188 MWh/ano & 30.896,6076 MWh/ano \\
\hline $\begin{array}{l}\text { Potência de cada célula } \\
\text { eletrolítica ligadas em série }\end{array}$ & & $450 \mathrm{KWh}$ \\
\hline $\begin{array}{l}\text { Quantidade de células eletrolíticas } \\
\text { existentes }\end{array}$ & 150 & 416 \\
\hline $\begin{array}{c}\text { Custo do GN/H2 por MWh gerado na } \\
\text { célula em } \mathrm{R} \$ / \mathrm{MWh}\end{array}$ & 221,49 & 221,49 \\
\hline
\end{tabular}




\section{O PROCESSO DE INTEGRAÇÃO - UMA SOLUÇÃO POSSÍVEL}

$\mathrm{Um}$ aproveitamento nobre do $\mathrm{H}_{2}$ para as indústrias do segmento cloro-soda está diretamente ligado no Brasil à matriz do GN (gás natural), que é deficitária, limitando à substituição do vetor energético para a produção de energia elétrica nas plantas do segmento, já que o óbice é o custo do gás. $\mathrm{O}$ custo do gás que substitui o hidrogênio não queimado é desfavorável, quando mantidas as atuais condições de contorno.

Em regiões como o nordeste do Brasil, para que não houvesse falta de gás natural para outros segmentos econômicos, foram despachadas termoelétricas a óleo que geram energia com elevados custos e emissão de poluentes atmosféricos, principalmente $\mathrm{CO}_{2}$ e compostos sulfurados, exigindo que as mesmas passassem a operar com capacidade ociosa, e assim, incrementando o consumo de óleo diesel e óleo combustível naquelas usinas que operam com esses insumos, atingindo em horários de pico de demanda tarifas ligeiramente superiores aos custos de geração de célula a combustível.

Em fevereiro de 2008, a situação dos reservatórios no Nordeste, onde a capacidade instalada de produção de energia elétrica divide-se em $96 \%$ de fontes hidráulicas e $4 \%$ de térmicas, com forte dependência com respeito ao índice pluviométrico que é a característica do setor elétrico nacional, foi de $35,23 \%$, inferior ao de janeiro de 2001 que atingiu a 41,39\%, quase reproduzindo o cenário de racionamento de consumo de energia elétrica ocorrido naquele ano de 2001, com real ameaça de que as indústrias que usam gás natural ficassem sem energia. $\mathrm{O}$ preço da energia no mercado spot, que representa uma parte pequena do mesmo, mas que sinaliza o grau de incerteza sob a oferta futura, atingiu em Janeiro de 2008 o valor de $\mathrm{R} \$ 502,00$ e recentemente reduziu-se para $\mathrm{R} \$ 256,00$, afastando o risco de racionamento admitido pela ANEEL (Agência Nacional de Energia Elétrica). No auge do receio de que fosse necessário, outra vez, o racionamento no Brasil, a alternativa proposta para o setor elétrico nacional foi justamente aumentar o uso das fontes poluidoras (óleo combustível, óleo diesel e carvão), que seria idêntico ao cenário de 2001 .

\section{COMO AVALIAR? ANÁLISE ECONÔMICA}

Tendo em vista as considerações expostas no trabalho, além do tradicional fluxo de caixa descontado (VPL), deve ser também utilizada a Teoria de Opções Reais, para o detalhamento do projeto de integração no cenário da viabilidade econômico-financeira, face à aleatoriedade dos parâmetros envolvidos, o que causa incertezas.

O método do VPL vem sofrendo críticas por ignorar opções implícitas em projetos (abandono, estratégia de crescimento e espera por melhores condiçôes - timing de investimento, por exemplo), levando a erros significativos quanto à incerteza e/ou flexibilidades que são relevantes no projeto.

$\mathrm{Na}$ Teoria de Opçôes Reais é considerada a natureza estocástica da evolução dos preços (ou de qualquer outra variável do modelo), com um modelo estocástico, enquanto no método do VPL, o preço para calcular a receita é o preço atual do mercado, uma seqüência, ou um valor esperado do preço na data em que o projeto iniciará a sua operação. Quando aplicada a projetos de investimentos, a TOR integra estratégia e finanças, considerando analiticamente as flexibilidades gerenciais e as opções implícitas nos projetos.

O princípio de neutralidade ao risco é uma boa ferramenta por permitir a superação de dois problemas de importância presentes nas técnicas tradicionais do VPL, que são:

- determinação da taxa de desconto;

- estimativa das probabilidades dos diversos cenários futuros.

Em um cenário neutro ao risco o retorno esperado para os ativos é a taxa livre de risco (r).

A regra de decisão pelo valor crítico (ou de gatilho) é derivada de um processo de otimização sob incerteza, sendo os dois métodos mais usados a seguir relembrados (MAJD; PINDYCK, 1987), que dão resultados equivalentes:

- Contingent claims;

- Programação dinâmica

A teoria das opções reais pode ser vista também como uma adequada combinação de árvores de decisão (podem ajudar a entender o processo decisório) com o VPL, desde que se utilizem probabilidades e taxas de desconto compatíveis. A tradicional abordagem de risco em projetos, a CAPM, 
embora não seja contraditória com a moderna teoria, é insuficiente para a análise de investimentos.

A Simulação de Monte Carlo (HAMMERSLEY; HANDSCOMB, 1964), útil em algumas aplicações, não é uma ferramenta de otimização e, assim, não é compatível para tomada de decisões.

$\mathrm{Na}$ presença de incertezas, como é o assunto abordado neste trabalho, a empresa moderna necessita de uma abordagem científica para a análise de investimentos. Para isso é necessário utilizar técnicas mais sofisticadas da teoria de probabilidade e técnicas de otimização dinâmica sob incerteza, nas quais a Teoria das Opções Reais possui sofisticadas ferramentas matemáticas, que consideram as flexibilidades gerenciais existentes nas oportunidades de investimento. Isto representa uma evolução na metodologia de análise de projetos para diversas aplicações em vários segmentos industriais, inclusive no segmento cloro-soda e projetos a serem desenvolvidos no Setor Elétrico Brasileiro.

\section{UM ESTUDO DE CASO - AVALIAÇÃO ECONÔMICA DA INTEGRAÇÃO}

Para atingir o objetivo deste trabalho, proceder-se-á a uma avaliação de um sistema de célula a combustível utilizando o hidrogênio obtido como subproduto de uma planta de cloro-soda (planta A), utilizando-se para isso as duas metodologias, o tradicional fluxo de caixa descontado (VPL) (ZOTES et al., 2006) e a Teoria das Opções Reais (TOR) (AMRAM; KULATILAKA, 1999).

A proposta a ser avaliada refere-se a uma modelagem, porém apresenta parâmetros possíveis com os que poderão ser praticados nas duas empresas brasileiras do segmento cloro-soda que, gentilmente, nos forneceram dados operacionais.

Os seguintes parâmetros serão utilizados como dados de entrada para as células:

- potência instalada/célula - 0,20 MW

- custo de investimento "aceitável" (KREUTZ; OGDEN, 2000), (MARNAY; CHARD, 2001) e Pilhas a combustível $^{5}$ - R\$ 20,6 milhóes

- custo de operação e manutenção - 0,01 $\mathrm{US} \$ / \mathrm{KWh}=(0,01 \mathrm{US} \$ / \mathrm{KWh})(15.200$

\footnotetext{
5 Workshop ANÁLISE, PROSPECTIVA DA INTRODUÇÃO DE TECNOLOGIAS ALTERNATIVAS DE ENERGIA NO BRASIL, Relatório preliminar. RJ: COPPE/UFRJ, 2002.
}

$\mathrm{KW} \times 8.760 \mathrm{~h} / \mathrm{ano})(1,7 \mathrm{R} \$ / \mathrm{US} \$)=$

\subsubsection{4,00 R\$/ano}

- preço do projeto - consumo de energia evitado (energia elétrica que deixará de ser comprada devido à geração de eletricidade oriunda do sistema da célula a combustível) $=\mathbf{R} \$ \mathbf{1 0 , 0}$ milhóes

- vida útil do equipamento - 12/20 anos e 5 anos para troca de stack

- taxa de desconto - 10 a $12 \%$ ao ano

- impostos - 14\% II, 5\% IPI e $17 \%$ ICMS, aproximadamente.

\subsection{AVALIAÇÃO POR FLUXO DE CAIXA DESCONTADO (VPL)}

Conforme o fluxo de caixa usado, o casobase do projeto apresenta os valores:

$\mathbf{V P L}=\mathbf{R} \$$ 35,12 milhões, a uma taxa de desconto de $12 \%$.

TIR $=36,34 \%$ (valor particular da taxa de desconto que anula o valor atual da distribuição do fluxo de caixa).

$\mathbf{I L}=\mathbf{2 , 7 1}$, relação entre o VPL e o Investimento inicial I.

(8) $\mathrm{IL}=(\mathrm{VPL}+\mathrm{I}) / \mathrm{I}($ ZOTES, 2006).

Para verificar a robustez da viabilidade econômica do projeto, por meio dos valores obtidos no VPL, ao se considerar uma taxa de desconto de $12 \%$, devem ser realizadas análises de sensibilidade para variações na referida taxa, nos custos operacionais e no preço da energia gerada pela célula a combustível.

As análises de sensibilidade realizadas mostraram que a variação do VPL em função da variação do custo de capital (taxa de desconto) resiste até uma taxa de desconto de $36,34 \%$, que é a TIR do projeto (VPL $>0$ ) e após o VPL se torna negativo, indicando a falta de viabilidade financeira do projeto.

Em função do valor do consumo evitado de energia elétrica (receita), numa variação sobre o caso-base de $-40 \mathrm{a}+60 \%$, o VPL é positivo, numa sensibilidade de $\mathrm{R} \$ 5,3$ a $\mathrm{R} \$ 80,0$ milhões, e correspondentes TIR de 15,88 a 66,0\%, devido à variação da receita de $\mathrm{R} \$$ 6,0 a $\mathrm{R}$ \$ 16,0 milhões.

Para a análise de sensibilidade em função dos custos operacionais referenciado, ao caso-base na faixa de $-40 \mathrm{a}+40$, o VPL é positivo, variando de $\mathrm{R} \$ 41,9$ a $\mathrm{R} \$ 28,4$, com TIR de 40,85 a $31,8 \%$, respectivamente. 
Como para cada MWh de $\mathrm{H}_{2}$ a ser consumido na célula a combustível, deverá ser adicionado $1 \mathrm{MWh}$ de GN para geração térmica, em substituição ao $\mathrm{H}_{2}$ utilizado atualmente para este fim, foram calculados VPLs que forneceram inicialmente TIR e VPL $<0$, de valores, respectivamente, zero e $\mathrm{R} \$ 188,56$ milhões, bem como IL = 8,15 , também negativo, mostrando que a energia gerada anteriormente não cobre, nas condiçôes atuais, o custo do gás ou de outra fonte que terá que ser comprada para suprir $\mathrm{o}_{2}$.

Há um custo adicional e permanente durante a vida útil do projeto que, mesmo com a receita oriunda do consumo evitado de energia térmica (economia gerada pelo aproveitamento do calor), o VPL não consegue suportar: VPL de valor negativo igual a R\$127,19 milhões, como também TIR e $\mathrm{IL}=5,17$, este também negativo, e, assim, o projeto ainda não se tornou economicamente viável.

$\mathrm{O}$ uso do hidrogênio nas células, que no momento presente é queimado para aquecimento das caldeiras das plantas, terá que ser substituído por GN, e, em alguns casos, adicionalmente por vapor, e que poderá também ser uma solução, cuja decisão estratégica é de responsabilidade das empresas e fora do escopo deste trabalho de pesquisa, que é a integração de célula a combustível em plantas de cloro-soda (VPL $=\mathrm{R} \$ 35,12$ milhões).

Com a inserção de bônus idênticos àqueles praticados na Europa Setentrional, Alemanha, Canadá e Japão (em escala menor), o projeto torna-se viável (VPL= R \$ 12,32 milhões). Se acrescido o bônus de redução de $\mathrm{CO}_{2}$ no valor de $0,05 €$ /Kwh (1 MW reduz 4600 t CO$_{2}$ /ano), obtido da mesma fonte acima citada, o projeto torna-se mais atraente, mesmo não sendo utilizado o bônus de $100 € /$ ton de $\mathrm{CO}_{2}$ não produzido (operação mais limpa) (VPL=139,30 milhões).

\subsection{ANÁLISE ECONÔMICA PELA TEORIA DAS OPÇÕES REAIS (TOR)}

A Teoria das Opções Reais quando aplicada a projetos de investimento integra estratégia e finanças, por considerar analiticamente as flexibilidades gerenciais e as opçôes implícitas no projeto, é o objetivo da estratégia empresarial (SOITO, 2002). Na abordagem do trabalho, o parâmetro decisório usado foi o do timing de investimentos, que pode ser entendido como o momento ótimo de decisão de investir ou não em um projeto.
A avaliação pela TOR apresenta um $\mathrm{V}^{*}=22,88$ milhões (a partir do qual é ótimo investir), maior que $\mathrm{V}=10,0$ milhões do caso-base, bem como o valor da opção de investir $\mathrm{F}(\mathrm{V})$, que cresce com a volatilidade $\sigma$, em função da evolução do valor do projeto, seguindo a mesma metodologia adotada quando da análise pelo VPL tradicional.

As duas ferramentas usadas mostram suas diferenças nos valores obtidos pela captura de incertezas na TOR devido ao estado da arte das células a combustível inerentes à integração proposta no trabalho, já que a regra de decisão através do valor (ou de gatilho), é derivada de um processo de otimização sob incerteza, utilizando-se as equações do modelo matemático de Portfolio Livre de Risco.

A seguir, mostra-se a análise econômica do projeto, utilizando-se a Teoria das Opções Reais, seguindo a mesma metodologia adotada quando da análise pelo VPL tradicional, como ferramenta de análise em um projeto de investimento, com os seguintes parâmetros de entrada:

- custo de investimento (I) - Os investimentos totais somam $\mathbf{R} \mathbf{\$ 2 0 , 6}$ milhóes

- valor do projeto $(\mathrm{V})-\mathbf{R} \mathbf{\$} \mathbf{1 0 , 0}$ milhóes

- taxa de juros livre de risco (r) $-\mathbf{5 \%}$

A taxa considerada é a taxa média nos últimos anos da remuneração dos títulos de renda fixa de longo prazo do tesouro americano (bonds) e foi escolhida porque esses títulos são considerados pelo mercado como parâmetro de investimentos livres de risco.

- taxa de distribuição do fluxo de caixa do projeto $(\delta)-9 \%$

Representa um custo de oportunidade (custo de não se produzir o bem, que no caso é o consumo evitado de energia elétrica), que pode ser representado pela taxa de distribuição do fluxo de caixa do projeto ou dividend yeld. Em outras palavras, é o custo de oportunidade de se manter a opção sem exercê-la, ou seja, o custo de adiamento. Os valores típicos se situam entre 2 e $12 \%$ e no nosso caso utilizou-se uma taxa de $9 \%$.

- volatilidade $(\sigma)-\mathbf{1 0} \%$ 
Considera o desvio-padrão da taxa de variação dos preços do projeto. A volatilidade do preço da energia elétrica, no presente estudo de caso, é diretamente proporcional à volatilidade de $\mathbf{V}$ para a qual, tendo em vista os dados de séries históricas disponíveis na literatura, utilizaremos uma volatilidade de $10 \%$.

Uma vez apresentados os parâmetros do modelo de opções reais, e utilizando-se as equações do modelo matemático de Portfolio Livre de Risco (SOITO, op. cit.), pode-se obter o valor crítico $\left(\mathrm{V}^{*}\right)$ a partir do qual é ótimo investir, bem como o valor da opção de investir $\mathrm{F}(\mathrm{V})$, cujas respectivas soluções são apresentadas:

$$
\begin{gathered}
F(V)=A V^{\beta}(\mathbf{9}) \\
V^{*}=(\beta / \beta-1) \times I(\mathbf{1 0})
\end{gathered}
$$

onde A é o valor residual do projeto, análogo a uma opção de venda do valor presente do projeto (V) em que o preço de exercício é igual ao valor residual $(\mathrm{A})$, e $\beta$, o quociente entre a covariância do retorno do valor do projeto $\mathrm{V}$ com o retorno do mercado e a variância do retorno do mercado $\sigma_{\mathrm{m}}{ }^{2}$, são dadas por

$$
\begin{array}{r}
A=\frac{V^{*}-I}{\left(V^{*}\right)^{\beta}}=\frac{(\beta-I)^{\beta-1}}{\beta^{\beta} \cdot I^{\beta-1}} \\
\beta=1 / 2-\frac{(1-\delta)}{\sigma^{2}}+\sqrt{\left[\frac{r-\delta}{\sigma^{2}}-1 / 2\right]^{2}+\frac{2 r}{\sigma^{2}}}
\end{array}
$$

e, conforme o exposto, os parâmetros envolvidos possuem os seguintes valores:

Tabela 4. Parâmetros do modelo de opçôes reais

\begin{tabular}{|c|c|}
\hline Parâmetros & Valor \\
\hline I Custo do investimento & $\mathrm{R} \$ 20,6$ milhões \\
\hline $\boldsymbol{\sigma}$ Volatilidade & $10 \%$ aa \\
\hline r Taxa de juros livre de risco & $5 \%$ aa \\
\hline $\boldsymbol{\delta}$ Taxa de dividendos & $9 \%$ aa \\
\hline
\end{tabular}

E, assim, os valores obtidos foram:

$$
\begin{aligned}
& \beta=1 / 2-(\mathrm{r}-\delta) / \sigma^{2}+\sqrt{\left(\mathrm{r}-\delta / \sigma^{2}-1 / 2\right)^{2}+2 \mathrm{r} / \sigma^{2}} \\
& =1 / 2-(0,05-0,09) / 0,1^{2}+
\end{aligned}
$$

$\sqrt{\left((0,05-0,09) / 0,1^{2}-1 / 2\right)^{2}+2 \cdot 0,05 / 0,1^{2}}=$ 10,0

$V^{*}=(\beta / \beta-1) . I=(3,81 / 2,81) \cdot 20,6=\mathbf{2 2 , 8 8}$ milhôes

$\mathrm{O}$ valor de $\mathrm{F}$ segue as seguintes condições

$\mathrm{F}(\mathrm{V}) \quad\left\{\begin{array}{l}\mathrm{AV}^{\beta} \text { para } \mathrm{V} \leq \mathrm{V}^{*} \\ \mathrm{~V} \text { - I para } \mathrm{V}>\mathrm{V}^{*}\end{array}\right.$

Como V=10,0 e $\mathrm{V}^{*}=22,88$ milhōes, o valor da opção de investir é dado por:

$\mathrm{F}(\mathrm{V})=\mathbf{A} \mathbf{V}^{\boldsymbol{\beta}}$

E, assim, vem:

$\mathrm{A}=\left(\mathrm{V}^{*}-\mathrm{I}\right) /\left(\mathrm{V}^{*}\right)^{\beta}=(22,88-20,6) / 22,88^{10,0}$

$=2,28 / 0,0484=5,79 \cdot 10^{-14}$

E,

$\mathrm{F}(\mathrm{V})=\mathrm{AV}^{\beta}=5,79 \cdot 10^{-14} \cdot 10,0^{10,0}=\mathbf{1 , 4 7}$

milhóes

Tabela 5. Valores obtidos

\begin{tabular}{|c|c|}
\hline Parâmetros & Valor \\
\hline$\beta$ (co-variança/variança) & 10,0 \\
\hline $\mathrm{V}^{*}$ (valor crítico) & 22,88 milhões \\
\hline $\mathbf{A}$ (valor residual) & $5,79 \times 10^{-14}$ \\
\hline $\mathrm{F}(\mathrm{V})$ (opção de investir) & 1,47 milhões \\
\hline
\end{tabular}

O valor da oportunidade de Investimento $\mathrm{F}(\mathrm{V})$ cresce com a volatilidade $\sigma$ :

- Para $\sigma=34,40 \%$ temos $\mathrm{V}^{*}=39,67$

- Para $\sigma=0,20 \%$ temos $\mathrm{V}^{*}=29,96$

- Para $\sigma=0,10 \%$ temos $\mathrm{V}^{*}=27,93$

Quanto maior a incerteza, expressa aqui pela volatilidade, maior será o valor da oportunidade de investimento $F(V)$ em função da evolução do valor do projeto.

No exame de um projeto usando a metodologia dos Direitos Contingentes da TOR (DIXIT; PINDYCK, 1995), deverão ser obtidos gráficos, 
conforme relacionados, para análise de sensibilidade do valor da oportunidade de investir em função da evolução do valor do projeto que em nosso caso será o consumo evitado (redução de custos com o consumo de energia elétrica).

- $\mathrm{F}(\mathrm{V}) \times \mathrm{V}$

- $\mathrm{V}^{*} \mathrm{x}$ Volatilidade $(\sigma)$

- $\mathrm{V}^{*} \mathrm{x}$ Taxa de Dividendos $(\delta)$

- $\mathrm{V}^{*} \mathrm{x}$ Taxa de Juros $(\mathrm{r})$

- $\mathrm{V}^{*} \mathrm{x}$ Investimentos

\section{DISCUSSÃO DOS RESULTADOS}

A integração de sistemas de célula a combustível com plantas que produzem hidrogênio, como a do segmento cloro-soda, representa uma solução para atingir concomitantemente as metas de ampliar a competitividade industrial e de contribuir para a política de redução de emissões de gases poluentes.

Os fabricantes internacionais, e de certa forma os nacionais, de sistemas de célula a combustível, estão dedicando muita importância para esses projetos de integração e realizando importantes pesquisas. Estas pesquisas estão focadas nos custos relativos ao ciclo de vida, nas corretas aplicações e em padróes de segurança, além da implementação de projetos de demonstração em parceria com empresas do segmento cloro-soda e fundos de investimento interessados em $\mathrm{P} \& \mathrm{D}$.

No Brasil, acordos específicos de trocas de informaçōes entre as universidades e fabricantes nacionais estão sendo programados para que assuntos de domínio público sejam publicados e as empresas do segmento sejam preservadas no que diz respeito aos seus interesses comerciais.

A partir dos dados obtidos, o custo por MWh gerado pelas células a combustível é muito sensível a uma quantidade importante de variáveis, tais como (investimento, fator de capacidade, impostos, usados nos cálculos de viabilidade econômico-financeira) e prazo de amortização. Os impostos federais - II (imposto de importação) e IPI (imposto sobre produtos industrializados) - podem ser eliminados por meio de um processo junto às autoridades fiscais, justificando a importância destes equipamentos como geradores de energia não poluentes e de alto rendimento. A experiência internacional mostra que nos países que utilizam esta tecnologia, não só são isentas de impostos como também os governos oferecem incentivos financeiros para fomentar sua utilização. Ainda, eliminando os impostos, temos uma variação de valor muito grande relativo ao tempo de amortização já citado e ao aproveitamento ou não do calor gerado, pois na célula a combustível do tipo PAFC, proposta neste trabalho, atinge a $200^{\circ} \mathrm{C}$, podendo ser usada para aquecimento de água para diversos fins.

Considerando 10 (dez) anos para amortização do capital, o único gasto adicional é a troca dos eletrodos após 5 (cinco) anos de funcionamento, com as considerações pertinentes. Além disto, existem outras possibilidades da redução de custo das células a combustível, através de incentivos que podem ser usados, como por exemplo, o Departamento de Defesa dos Estados Unidos possui um programa de incentivo para a utilização desses equipamentos, permitindo um reembolso de U\$ 1.000 por KW instalado. Outras possibilidades incluem financiamento de entidades como Banco Mundial ou o Banco Interamericano de Desenvolvimento - BID para a utilização dessas tecnologias não poluentes, com pequenas taxas de juros.

Como citado anteriormente, outros países, dentro do espírito do protocolo de Kyoto e de outros tratados internacionais que promovem a utilização de tecnologias menos agressivas ao meio-ambiente, como Alemanha, países da Europa Setentrional e, em menor escala, Japão e o Canadá, onde a legislação ambiental está se tornando extremamente restritiva (SERRA, op. cit.), oferecem créditos (bônus) por tonelada de $\mathrm{CO}_{2}$ não produzido (operação mais limpa).

As emissóes da célula a combustível proposta do tipo PAFC $^{6}$, são listadas a seguir:

- $\mathrm{CO}-6 \mathrm{ppm}$

- $\mathrm{NO}_{\mathrm{x}}-5 \mathrm{ppm}$

- $\mathrm{SO}_{2}-6 \mathrm{ppm}$

- $\mathrm{H}_{2}-15 \mathrm{ppm}$

Em regime estacionário, as emissões de poluentes atmosféricos, oriundos da célula proposta do tipo PAFC, são provenientes do ciclo completo de produção de energia elétrica, incluindo a reforma de hidrocarbonetos para a geração de hidrogênio, $o$

\footnotetext{
${ }^{6}$ CANTÃO et al. WORKSHOP INTERNACIONAL SOBRE CÉLULAS A COMBUSTÍVEL (WICaC), 2, Campinas: UNICAMP.
} 
que permite o uso dos bônus referidos (menores do que as outras fontes usadas para obtenção de energia elétrica). Some-se a isso o fato de que o objetivo da integração é mais atrativo no que diz respeito aos índices referidos de emissão de poluentes, por não precisar de reforma do hidrogênio, já que a célula a combustível é alimentada por hidrogênio produzido por células eletrolíticas do tipo membrana, considerado suficientemente puro.

Em situações especiais, onde são necessários cuidados adicionais com a poluição ambien- tal e sonora, ou ainda os casos onde existe um forte apelo pela qualidade da energia fornecida e pela confiabilidade do fornecimento, as células a combustível já são competitivas economicamente há mais de 10 (dez) anos (CANTÃO et al., 2002).

Com respeito à qualidade referida, é mostrada, a seguir, a participação em diversos parâmetros elétricos com as respectivas caracterizaçôes em testes realizados no Lactec-Curitiba, em março de 2002 (CANTÃO, 2004):

Tabela 5. Testes realizados no Lactec-Curitiba sobre qualidade de energia elétrica

\begin{tabular}{|c|c|c|}
\hline Parâmetro & Planta desconectada & Planta conectada \\
\hline Tensões RMS & Estáveis e equilibradas & Estáveis e equilibradas \\
\hline Correntes e potências ativas RMS & Levemente desequilibradas & $\begin{array}{c}\text { Mais equilibradas em todas as } \\
\text { potências }\end{array}$ \\
\hline Potências reativas & Fortemente desequilibradas & Fortemente desequilibradas \\
\hline Distorção total harmônica de tensão & $1,9 \%<\mathrm{DTHv}<4,2 \%$ & $1,9 \%<\mathrm{DTHv}<6,0 \%$ \\
\hline Distorção total harmônica de corrente & $23 \%<\mathrm{DTHi}<75 \%$ & $\mathbf{2 0 0 K W : 1 0 \% < D T H i < 2 5 \%}$ \\
\hline Fator de potência & $0,8<\mathrm{f}_{\mathrm{p}}<0,95$ & $\mathbf{2 0 0 K W : ~} \sim \mathbf{1}$ \\
\hline
\end{tabular}

\section{CONCLUSÓES}

O projeto de integração de sistemas de célula a combustível dentro nas plantas de cloro-soda para utilização do hidrogênio gerado pelo processo, pode ser viável dependendo de três variáveis possíveis de ação governamental, a saber: preço da energia elétrica, preço do gás e de subsídios possíveis de serem praticados. A aplicação do VPL e da TOR ao uso do $\mathrm{H}_{2}$ oriundo de plantas $\mathrm{Cl}-\mathrm{Na}$ em sistemas de células a combustível mostra que a energia gerada pelo uso do $\mathrm{H}_{2}$ nas células, anteriormente utilizado para produzir calor necessário para o processo, nas condições atuais, não cobre o custo do gás ou outra fonte que terá que ser comprada para suprir o $\mathrm{H}_{2}$ Há um custo adicional e permanente durante a vida útil do projeto que, mesmo com a receita oriunda do consumo evitado de energia térmica (economia gerada pelo aproveitamento do calor) ${ }^{7}$,

\footnotetext{
7 Lembra-se que as células a combustível de ácido fosfórico de $200 \mathrm{~kW}$, operando em regimes de funcionamento dife-
}

não consegue ser suportado, e assim o projeto ainda não é economicamente viável.

O preço de $\mathrm{R} \$ 221,49 / \mathrm{MWh}$ para o $\mathrm{GN}$, foi obtido a partir do valor de $\mathrm{R} \$ 22,21 / \mathrm{GJ}$ para indústria, conforme (SERRA, 2005).

Oportuno ressaltar que o preço acima, para a compra do GN para substituir o $\mathrm{H}_{2}$ utilizado nas células, refere-se à tarifa comercial da CEG, no Rio de Janeiro. Acontece que o segmento cloro-soda recebe o GN diretamente da Petrobras, empresa que não disponibiliza a tarifa real, caracterizando a fragilidade do custo adicional obtido pela não utilização de $\mathrm{H}_{2}$ como combustível em substituição ao gás natural.

$\mathrm{Na}$ mesma fonte são mostrados comparativamente os preços dos principais combustíveis:

rentes, podem gerar somente energia elétrica, ou elétrica/ térmica (mais $200 \mathrm{kWt}$ ). 
Tabela 7. Preços comparativos de combustiveis

\begin{tabular}{|c|c|}
\hline Combustíveis & $(\mathrm{R} \$ / \mathrm{GJ})$ \\
\hline Gás natural & $14 \mathrm{a} 45$ \\
\hline GLP & 48 \\
\hline Etanol hidratado & 74 \\
\hline Metanol & 67 \\
\hline Gasolina & 67 \\
\hline Diesel & 42 \\
\hline
\end{tabular}

$\mathrm{Na}$ tabela 7, são listados os preços de fontes energéticas alternativas ao GN, onde se observa que os mesmos suplantam o valor do gás natural, que é entregue pela Petrobrás ${ }^{8}$ às distribuidoras estaduais por $\mathrm{R} \$ 8,7 / \mathrm{GJ}$ e estas adotam critérios próprios de tarifação que diferem bastante entre si. ${ }^{9}$

$\mathrm{Na}$ mesma tabela, a faixa de preços de GN foi baseada nas tarifas de jan/2003 das distribuidoras da área de atuação da CHESF (Companhia Hidroelétrica do São Francisco), na região Nordeste, aplicadas a consumidores residenciais e comerciais.

Com exceção do metanol, os demais preços da tabela referida são preços médios nacionais de fevereiro/março/2003, segundo levantamento da ANP (Agência Nacional do Petróleo), feito periodicamente junto a revendedores. ${ }^{10}$ Com respeito ao metanol, o preço da tabela é arbitrário, porque no início da década de 90 foi importado para ser usado como combustível, e foi tarifado nos postos de distribuição com preço equivalente ao do álcool e da gasolina. O preço da tabela corresponde ao valor necessário para equipará-lo aos dois combustíveis em $\mathrm{R} \$ / \mathrm{KJ}$. A produção nacional atende à metade do consumo e o restante é importado, e os preços internacionais, para comercialização em grande quantidades, variam bastante no tempo, conforme seus valores históricos. ${ }^{11}$ É fabricado a partir do GN, basicamente para uso na indústria química, sendo fabricado no Brasil pelas empresas Prosint e Methanor.

As considerações anteriores mostram que as empresas do segmento cloro-soda, no Brasil, es-

\footnotetext{
${ }^{8}$ Ver www.ctgas.com.br/gasnatural/preços.html.

9 As tarifações são encontradas nas páginas das distribuidoras ou no site http://www.gasnet.com.br/gasnet_br/cogeração/tarifas_gas_natural.htm.

${ }^{10} \mathrm{~V}$. http://www.anp.gov.br/preços/aberto.asp.

${ }^{11} \mathrm{http}: / /$ www.methanex.com/methanol/currentprice.htm.
}

tão "engessadas", de um lado pelas tarifas de energia elétricas, e, do outro, pelo preço do GN para substituir o $\mathrm{H}_{2}$, a ser utilizado nas células, visando a atender às necessidades térmicas das plantas do segmento cloro-soda.

Finalmente, pode-se concluir que, com a tecnologia reinante e os custos incorridos, o projeto de uso de células a combustível dentro das plantas de cloro-soda para utilização do hidrogênio industrial, ficará com a sua atratividade vinculada a decisões do governo brasileiro de utilização dos bônus citados, igualando-se àqueles países referidos, em sintonia com os protocolos ambientais.

\section{REFERÊNCIAS}

AGÊNCIA NACIONAL DE ENERGIA ELÉTRICA - ANEEL: Disponível em: http://www. aneel.gov.br/cedoc/reh2004268.pdf . Acesso em: junho/2008.

AGÊNCIA NACIONAL DE PETRÓLEO, GÁS NATURAL E BIOCOMBUSTÍVEIS - ANP. Disponível em: http://www.anp.gov.br/preços/ aberto.asp. Acesso em nov/2008.

AMRAN, Martha; KULATILAKA, Nalin. Real Options: Managing Strategic Investment in an Uncertain World. Boston, Mass.: Harward Business School Press, 1999.

BLACK, F.; SCHOLES, Myron. The Pricing of Options and Corporate Liabilities. In: Journal of Political Economy, no 81, 1973.

BREALEY, R.A.; MYERS, S.C. Principles of corporate finance. 6a ed., New Yok: McGraw-Hill, 2001.

BURANI, Geraldo Francisco; MARUYAMA, Flávio Minora; MORALES UDAETA, Miguel Edgar. Introdução da produção energética através de células de combustível no planejamento energético. In: LATIN-AMERICAN CONGRESS: ELECTRICITY GENERATION AND TRANSMISSION , 5. 2003, São Pedro. Proceedings, São Pedro: UNESP/Valparaiso Catholic University/National University of Mar del Plata, 2003. 8p. 
CAMPBELL, K. R. Residencial Fuel Cells: The Race Toward Commercialization, 2001. Apud SERRA, E. T.; FURTADO, J. G. de M.; SOARES, G. F. W.; CODECEIRA NETO, A. Células a combustivel: Uma alternativa para Geração de Energia e sua Inserção no Mercado Brasileiro. RJ: Centro de Pesquisas de Energia Elétrica - CEPEL, 2005.

CANTÃO, M. P.; IMPINNISI, P. R.; PARANHOS, J. M. R. Implantação e Avaliação da Tecnologia de Células a Combustivel. Curitiba: CEPEL-LACTEC, 2002.

CANTÃO, Maurício P. Células a Combustivel de Ácido Fosfórico: Experiência e Perspectivas. In: WORKSHOP INTERNATIONAL DE CÉLULA COMBUSTIVEL (WICaC), 2. 2004, Anais..., UNICAMP: 2004.

CENTRO DE TECNOLOGIAS DO GÁS CTGÁS. http://www.ctgas.com.br/gasnatural/ preços.html. Acesso em: nov/2008.

COX, John C.: Ross, Stephen A.; RUBINSTEIN, Mark. Option Pricing: A Simplified Approach. Journal of Financial Economics, vol. 7, p. 229-263. 1979.

DAMODARAN, A. The promise end peril of real Options, working paper, Stern School of Business. Disponível em: www.stern.nyu.edu/adamodaran. 2000. Acesso em: maio/2008.

The dark side of valuation: firms with no earnings, no history, no comparables - can Amazon. com. be valued? working paper, Stern School of Business. Disponível em: www.stern.nyu. edu/adamodaran. 2000. Acesso em: maio/2008.

DEPARTAMENT of Defense (DOD). DOD Fuel Cell/PAFC Demonstration Program. Disponível em: http://www.dodfuelcell.com/pafc/site_performance.php3_jan/2003. Acesso em: jan/2008.

DIXIT, A. K.; PINDYCK, Robert S. Investment Under Uncertainty. Princeton, New Jersey: Princeton University Press. 1995.

HAMMERSLEY, J. M.; HANDSCOMB D. C.. Monte Carlo Methods. Londres: Methuen \&Co., Princeton University Press, 1964.
KREUTZ, T. G.; OGDEN, J.M. Assesment of Hydrogen Fueled Proton Exchange Membrane Fuel Cells for Distributed Generation and Cogeneration, Proceedings of the 2000 U.S. DOE Hydrogen Program Review, U.S.: Department of Energy, 2000.

LOKURLU, A.; GRUBE, T.; HÖHLEIN, B; STOLTEN, D. Fuel Cells for mobile and stationary applications - cost analysis for combined heat and power stations on the basis of fuel cells. International Journal of Hydrogen Energy, 28, 2003. p. 703-711.

MCDONALD, R.; D, SIEGEL. The Value of Waiting to Invest. The Quartely Journal of Economics, 101, 1986. p. 207-227.

MAJD, S.; PINDYCK, R. Time to Build, Option Value, and Investment Decisions, Journal of Financial Economics, 18, North-Holland, 1987. p. 7-27.

MARNAY, C; CHARD, J. S. Modeling of Customer Adoption of Distributed Energy Resources, Consortium for Electric Reliability Technology Solutions, California Energy Commission, Califórnia, ago/2001.

METHANEX CO. Disponível em: http://www. methanex.com/methanol/currentprice.htm. Acesso em: nov/2008.

O site do Gás - GAsNet. Disponível em: http:// www.gasnet.com.br/gasnet_br/cogeração/tarifas_ gas_natural.htm. Acesso em: nov/2008.

SERRA, E. T.; FURTADO, J. G. de M.; SOARES, G. F. W.; CODECEIRA NETO, A. Células a combustivel: Uma alternativa para Geração de Energia e sua Inserção no Mercado Brasileiro. RJ: Centro de Pesquisas de Energia Elétrica - CEPEL, 2005. 186 p.

SOITO, João Leonardo S. A Teoria das Opções Reais como Ferramenta na Avaliação de um Investimento de Capital no Setor Elétrico Brasileiro. 2002. p. 218f. Dissertação (Mestrado em Planejamento Energético) - UFRJ, Rio de Janeiro, 2002.

TRIGEORGIS, Lemos. The Nature of Options Interactions and the Valuation of Investment with Multiple Real Options. Journal of Financial and Qualitative Analysus, 1993. vol. 28, no 1, p. 202224. 
ZOTES, Péres Luis; BORDEAUX-RÊGO, Ricardo; GORET, Pereira Paula; SPRITZER, Ilda Maria de Paiva Almeida. Viabilidade econômicofinanceira de projetos. Rio de Janeiro: FGV, $1^{\mathrm{a}} \mathrm{ed}$. 2006. Reimpressão 2006, 2007.

WORKSHOP ANÁLISE PROSPECTIVA DA INTRODUÇÃO DE TECNOLOGIAS ALTERNATIVAS DE ENERGIA NO BRASIL, 2002, local. Pilhas a combustivel - relatório preliminar, RJ: COPPE/UFRJ, 2002.

WOKSHOP NATIONAL HYDROGEN ENERGY ROADMAP - NHERM. Washington D.C., Departament of Energy (US DOE 2002a). Disponível em: http://www.eere.energy.gw/hidrogenandfuelcells/pdfs/national_h2_roadmap.pdf. Acesso em: fev/2006. 